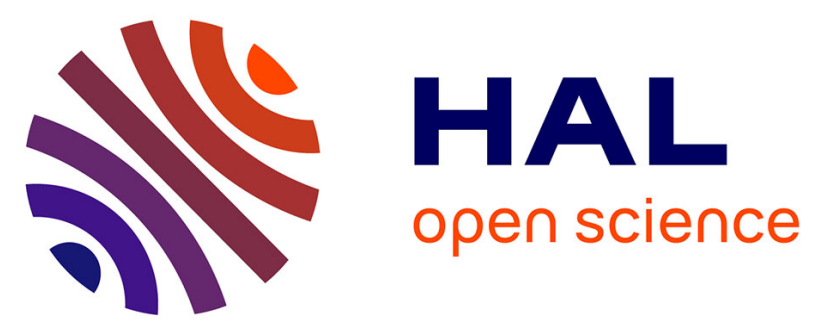

\title{
A BRCA2 mutation incorrectly mapped in the original BRCA2 reference sequence, is a common West Danish founder mutation disrupting mRNA splicing
}

Mads Thomassen, Inge Søkilde Pedersen, Ida Vogel, Thomas V. O. Hansen, Charlotte Brasch-Andersen, Claus L. Brasen, Dorthe Crüger, Lone Sunde, Finn C. Nielsen, Uffe B. Jensen, et al.

\section{To cite this version:}

Mads Thomassen, Inge Søkilde Pedersen, Ida Vogel, Thomas V. O. Hansen, Charlotte BraschAndersen, et al.. A BRCA2 mutation incorrectly mapped in the original BRCA2 reference sequence, is a common West Danish founder mutation disrupting mRNA splicing. Breast Cancer Research and Treatment, 2010, 128 (1), pp.179-185. 10.1007/s10549-010-1272-6 . hal-00615388

\section{HAL Id: hal-00615388 \\ https://hal.science/hal-00615388}

Submitted on 19 Aug 2011

HAL is a multi-disciplinary open access archive for the deposit and dissemination of scientific research documents, whether they are published or not. The documents may come from teaching and research institutions in France or abroad, or from public or private research centers.
L'archive ouverte pluridisciplinaire HAL, est destinée au dépôt et à la diffusion de documents scientifiques de niveau recherche, publiés ou non, émanant des établissements d'enseignement et de recherche français ou étrangers, des laboratoires publics ou privés. 
A BRCA2 mutation incorrectly mapped in the original BRCA2 reference sequence, is a common West Danish founder mutation disrupting mRNA splicing

Mads Thomassen, Inge Søkilde Pedersen, Ida Vogel, Thomas v. O. Hansen, Charlotte BraschAndersen, Claus L Brasen, Dorthe Crüger, Lone Sunde, Finn C. Nielsen, Uffe B. Jensen, Marie Luise Bisgaard, Åke Borg, Anne-Marie Gerdes, Torben A. Kruse

Affiliations:

MTH, TAK, CBA: Department of Clinical Genetics, Odense University Hospital, Denmark

IV, UBJ: Department of Clinical Genetics, Aarhus University Hospital, Skejby, Denmark

CLB: Department of Biochemistry and Pharmacology, Odense University Hospital, Denmark

ISØ: Section of Molecular Diagnostics, Department of Biochemistry, Aalborg University Hospital, Denmark

TVOH, FCN: Section of Genomic Medicine, Department of Clinical Biochemistry, Rigshospitalet, Copenhagen, Denmark

LS: Department of Clinical Genetics, Aalborg Sygehus, Aarhus University Hospital and Dept. of Human Genetics, Aarhus University

DC: Department of Clinical Genetics, Vejle Hospital

AB: Department of Oncology, Clinical Sciences, Lund University, Sweden

AMG: Department of Clinical Genetics, Rigshospitalet, Copenhagen, Denmark

MLB: Department of Cellular and Molecular Medicine, Copenhagen University, Blegdamsvej 3, 2200 Copenhagen N, Denmark.

Corresponding author: Mads Thomassen: Department of Clinical Genetics, Odense University Hospital, Denmark. Tlf: 0045 65412839, Fax: 004565411911

Key words: hereditary breast cancer; BRCA2; 7845+1G>A; founder mutation; mutation age; SNP array; RT-PCR

\begin{abstract}
Inherited mutations in the tumor suppressor genes BRCA1 and BRCA2 predispose carriers to breast and ovarian cancer. We have identified a mutation in BRCA2, 7845+1G>A (c.7617+1G>A), not previously regarded as deleterious because of incorrect mapping of the splice junction in the originally published genomic reference sequence. This reference sequence is generally used in many laboratories and it maps the mutation 16 base pairs inside intron 15. However, according to recent reference sequences the mutation is located in the consensus donor splice sequence. By reverse transcriptase analysis, we demonstrate loss of exon 15 in the final transcript interrupting the open reading frame. Furthermore, the mutation segregates with a cancer phenotype in 18 Danish families. By genetic analysis of more than 3500 Danish breast/ovarian cancer risk families, the mutation was identified as the most common BRCA2 mutation in West Denmark, while it is rare in Central and East Denmark and not identified in South Sweden. Haplotype analysis using dense SNP arrays indicates a common founder of the mutation approximately 1500 years ago.
\end{abstract}




\section{Introduction}

Breast cancer is the most common female cancer in the western world affecting more than $10 \%$ of women. Approximately 5-10\% of cases are believed to be inherited [1]. Germline mutations in the BRCA1 and BRCA2 genes predispose to breast and ovarian cancer and to a lesser extend to other cancers. The two genes have been used increasingly for clinical diagnostics and prognosis during the last 10-15 years. In Denmark, mutations in the two genes are identified in $28 \%$ of high risk families which is comparable to other western populations [2]. The relatively low frequency of mutations in the high risk families indicates the influence of other genes or insufficient analysis of BRCA1 and BRCA2. For example promoters and the majority of intron sequences are usually not analyzed and interpretation of variants in these regions is difficult. Even for variations located near the consensus AG and GT acceptor and donor splice sites, functional analyses are necessary to reveal splice defects. Furthermore, the applied techniques do not have $100 \%$ sensitivity, resulting in missed mutations. High quality cDNA and genomic reference sequences are essential to ensure correct interpretation of gene structure and clinical significance of identified variations.

The mutational spectrum for BRCA1 and BRCA2 is wide and analysis of entire coding regions and flanking sequences is necessary in most populations. However, founder mutations are evident in isolated genetic populations like the inhabitants in Iceland [3], Norway [4], Greenland [5] and among Ashkenazi Jews [6]. We have previously reported the mutational spectrum in BRCA1 and BRCA2 and only found weak indications of local founder mutations in Denmark [7]. However, at that time a mutation in BRCA2 intron 15, was interpreted as likely non deleterious in most Danish laboratories because of an error in the mapping of the splice junction in the reference sequence. Here we have performed functional analysis of the mutation, and we have analyzed the prevalence and the geographical distribution of the mutation in Denmark and Southern Sweden in samples forwarded for mutation screening from departments of clinical genetics. Moreover, the genetic origin and the age of the mutation were addressed by haplotype analysis using dense SNP arrays.

\section{Materials and methods}

Mutation analysis

BRCA1 and BRCA2 testing was requested after genetic risk assessment and counseling at the departments of clinical genetics. Blood samples were preferably collected from affected index persons. In some families no affected persons were alive and indirect testing was performed on a number of healthy relatives [8]. Mutation analysis of Danish samples was performed in 4 separate laboratories (Aalborg, Odense, Copenhagen, and Lund). Analysis of Swedish samples was performed in Lund. Mutation screening was performed by slightly different techniques, but most laboratories performed prescreening by DHPLC (denaturing high-performance liquid chromatography) and in some laboratories TGCE (Temperature Gradient Capillary Electrophoresis [9]) and PTT (Protein Truncation Test [10]) followed by sequencing of relevant regions. MLPA (Multiplex Ligation dependent Probe Amplification) was used to identify large genomic rearrangements. As part of these screenings, the exon 15 region of BRCA2 was analyzed by MLPA, TGCE, DHPLC and/or sequencing.

\section{Reverse transcriptase PCR}

Total RNA was extracted from blood from a carrier of $7845+1 \mathrm{G}>\mathrm{A}$ using TRI reagent (Sigma) according to manufacturer's instructions. Random hexamer primed reverse transcription was carried out using SuperScriptIII (Invitrogen) at $50^{\circ} \mathrm{C}$ for $60 \mathrm{~min}$, according to manufacturer's instructions. Primers (c2EX14F: 5' GGA GGA AAA CAG ACA AAA GC 3' and c2EX16R: 5' CAT CCA CCA 
TCA GCC AAC 3') encompassing exon 15 of BRCA2 were designed. PCR was carried out using AmpliTaq DNA polymerase with GeneAmp10XPCR buffer II (Applied Biosystems) in the presence of $2 \mathrm{mM} \mathrm{MgCl}{ }_{2}$ under the following conditions: $95^{\circ} \mathrm{C}$ for $2 \mathrm{~min}$ followed by 38 cycles of $95^{\circ} \mathrm{C}$ for $30 \mathrm{~s}$, $58^{\circ} \mathrm{C}$ for $30 \mathrm{~s}$ and $72^{\circ} \mathrm{C}$ for $60 \mathrm{~s}$, and finally $72^{\circ} \mathrm{C}$ for $2 \mathrm{~min}$. The PCR products were sequenced in both directions using a 3130XL Genetic Analyzer (Applied Biosystems).

To estimate the frequency of exon 15 skipping from the mutated allele, we used peak heights in positions in the sequence with dual base calls corresponding to exon 15 and 16 in the forward sequence and exon 14 and 15 in the reverse sequence. The fraction of loss was calculated as $\mathrm{F}=\mathrm{h} 2 /(\mathrm{h} 2+(\mathrm{h} 1$ $\mathrm{h} 2) / 2$ ) were $\mathrm{h} 1$ and $\mathrm{h} 2$ are the heights of the two peaks in one position; h1 representing the base of the wild type allele and $\mathrm{h} 2$ representing the base of the mutated allele. This formula assumes equal expression of both alleles. The percentage of loss was calculated as the mean value of $\mathrm{F}$ for 10 dual base positions in each sequence multiplied with $100 \%$.

$\underline{\text { SNP array analysis }}$

Genome-Wide Human SNP 5.0 Arrays (Affymetrix) were used according to manufacturer's instructions. Briefly, two aliquots of $250 \mathrm{ng}$ DNA were digested with Sty1 and Nsp1, respectively. Adaptors containing universal primer sites were ligated to the fragment ends and fragments were amplified in multiplex PCR. Purified PCR products were hybridized to 5.0 chips that were subsequently washed and scanned and cel files were generated. Genotypes were called from cel files using BRLMM-P algorithm. All chips had present call rates above the QC limit of 86\%, except one chip with $83 \%$, which is allowed according to Affymetrix analysis guidelines. One chip was excluded because of lower present call rate resulting in 18 informative arrays representing 18 families. A common haplotype was estimated as the most common allele for each SNP on chromosome 13. The length of the haplotype was estimated in each individual as the longest fragment including BRCA2 without a homozygous SNP discordant with the common haplotype. The genetic lengths of the haplotypes measured in $\mathrm{cM}$ were calculated using recombination rates from UCSC (http://genome.ucsc.edu). The age of the mutation was calculated by assuming 100 generations to generate haplotypes of $1 \mathrm{cM}$ and an average generation time of 25 years.

\section{Pedigree analysis}

Pedigrees from all families were constructed by the clinical genetic departments. Genetic testing of affected and healthy family members allowed co-segregation analysis of the mutation with the breast and ovarian cancer phenotypes. We calculated a likelihood ratio as proposed by Mohammadi et al [11]. This method use penetrance as a function of age of onset, thereby avoiding the use of discrete liability classes used in LOD score methods. Furthermore, we applied their method to calculate the combined likelihood score across families as the product of individual likelihood ratios.

\section{Results}

As part of the routine screening for mutations in BRCA1 and BRCA2 we identified a G>A substitution in intron 15 of BRCA2. According to the genomic sequence originally reported [12], X95165, the identified variation was mapped 16 bases within intron 15. This reference sequence was also recommended by BIC (Breast Cancer Information Core) at that time. Furthermore, the entries in BIC still refer to exon/intron boundary at position 7829 in the cDNA in agreement with X95165. There are four entries for 7829+1G>A, 3 from Myriad and one of Danish origin reported by Bergthorsson et al [13]. However, Bergthorsson named it $7845+1 \mathrm{G}>\mathrm{A}$ in their publication. Furthermore, the mutation has 
been reported in one Spanish family [14]. We observed misalignment to X95165 when sequencing the region. We therefore consulted more recent reference sequences that concurrently mapped the exon/intron boundary to position 7845 , resulting in reclassification of the mutation as interrupting the consensus $\mathrm{G}$ in first position of the splice donor site in intron 15.

In general we interpret a mutation in this position as deleterious. However, disruption of the consensus donor site may lead to an in-frame transcript that may not be deleterious. Furthermore, because of the disagreement of the reference sequences, we decided to perform functional splice analysis of the mutation. We isolated RNA from lymphocytes sampled from a carrier of the mutation for RT-PCR analysis. By using PCR primers located in exon 14 and 16 and sequencing the product, we obtained a mixed sequence in agreement with loss of exon 15 on one allele (figure 1). To estimate the fraction of loss of the mutated allele we calculated the percentage of mRNA missing exon 15 compared to the expected total amount of mutated allele. The values were $94 \%$ for exon 15 compared to exon 16 in the forward sequence and $90 \%$ for exon 15 compared to exon 16 in the reverse sequence, respectively. In conclusion the mutation causes almost complete loss (approximately 92\%) of exon 15 in RNA from the mutated allele. Loss of the 192 bases will result in frame shift and stop codon 7 amino acids after exon 14.

Of the 19 identified families, pedigrees were available from 18. This information is summarized in table 1 . To confirm that the mutation is deleterious, we calculated likelihood ratio for co-segregation of the mutation and breast and ovarian cancer. A significant exception for the segregation pattern was observed in family 1, where a female non-carrier developed bilateral breast cancer (54 and 60 years), resulting in a likelihood ratio of 0.0095 . However, the likelihood ratios were near 1 or higher in the remaining families and the overall ratio across all families was 1,662,078 (table 1).

The patients included in the study were from 5 regions. The peninsula Jutland in West Denmark contains Aalborg in the north, Aarhus in the upper middle, Vejle in the lower middle and South Jutland. The island Funen is in the southern middle part of Denmark and East Denmark containing half of the Danish population is composed of Zealand and smaller islands (Figure 2). Our analysis revealed a skewed distribution of the mutation: more than half of the $7845+1 \mathrm{G}>$ A families were located in Vejle area; whereas only $13 \%$ of families undergoing genetic screening of BRCA1 and BRCA2 were from this area (466/3690, table 2).

Compared to East Denmark where the $7845+1 \mathrm{G}>\mathrm{A}$ mutation was identified only once in 1300 mutation screenings, higher frequencies were observed in Jutland. When these frequencies were compared to the number of mutation screenings, significantly higher frequencies were found for Aarhus $(\mathrm{p}=0.03)$ and Vejle $(\mathrm{p}=0.00001)$ whereas it was borderline significant for Aalborg $(\mathrm{p}=0.07)$. Similarly, when the number of families with $7845+1 \mathrm{G}>\mathrm{A}$ mutations was compared to the number of families with identified pathogenic mutations in BRCA1 and BRCA2, increased frequencies for Vejle $(\mathrm{p}=0.000005)$, Aarhus $(\mathrm{p}=0.016)$ and Aalborg $(\mathrm{p}=0.049)$ were found compared to East Denmark (Figure 2). An insignificantly higher frequency of 7845+1G>A was found in South Jutland and Funen compared to East Denmark. The mutation was not identified in South Sweden supporting its skewed distribution.

To clarify if the $7845+1 \mathrm{G}>\mathrm{A}$ mutation had one common founder, we analyzed DNA from index persons from 18 of the 19 families using SNP arrays. Of the 500K SNPs, approximately $17 \mathrm{~K}$ was located on chromosome 13. The longest shared haplotype was estimated from the most common allele for each SNP. The ends of the haplotypes were limited by SNPs that were homozygous and different from the common type (red in figure 3). The results are in agreement with one common founder haplotype. The length of the shared haplotype ranged from $0.2 \mathrm{Mb}$ to $3.3 \mathrm{Mb}$ corresponding to 415 and 
23 generations respectively. The mean number of generations across all chips was 63.8 and assuming 25 years for each generation the mutation was founded 1500 years ago in the Danish Iron Age.

\section{Discussion}

We have identified a mutation that may be misinterpreted because of an error in the previously used reference sequence. Many laboratories tend to use a fixed reference sequence to ensure consistency in nomenclature. However, our results highlight the importance of using updated reference sequences.

We have confirmed that the identified mutation is most likely to be deleterious by calculating likelihood ratios for co-segregation and by RT-PCR analysis. For one family a disagreement with cosegregation was observed, because a woman with bilateral breast cancer turned out to be a non-carrier. However, no deleterious BRCA1 and BRCA2 mutations were identified in $84.7 \%$ of the women with bilateral breast cancer diagnosed at a mean age of 46 years in the WECARE study [15] supporting that our case is a phenocopy. Another potential phenocopy, a non carrier from family 4 developed breast cancer 39 years old. However, 5 other affected women in that family were all mutation positive and the resulting LR was 57.35 supporting co-segregation of disease and breast and ovarian cancer. The overall likelihood ratio for all families was 1,662,078, strongly supporting co-segregation of the mutation with the disease.

RT-PCR analysis demonstrated skipping of exon 15. Quantification of the mutated and the wildtype alleles indicated that exon 15 is lost in approximately $92 \%$ of mRNAs produced by the mutated allele, suggesting slightly reduced penetrance of this mutation. However, correct splicing using a nonconsensus donor site is highly unlikely and the result may reflect uncertainty in the measurement. The most likely explanation for the observation that the RNA lacking exon 15 did not constitute $50 \%$ of mRNA, is nonsense mediated decay of mRNA because of premature termination of transcripts. The results are in agreement with Gutierrez-Enriquez et al. [14], although they did not quantify the the fraction of exon 15 loss.

The age of the mutation may seem relatively high (1500 years) taking its skewed location into account i.e. the strong over-representation in central Jutland compared to the rest of Denmark. This may be surprising because the Danish population is regarded genetically homogeneous with no genetically isolated sub-regions. The most obvious explanation may be that the mutation was founded in the Vejle area, and that individuals carrying this mutation have not tended to move to Funen and East Denmark. Another potential explanation could be that the mutation was missed in some laboratories. However, this is highly unlikely because all Danish laboratories identified the mutation at least once and the mutation was confirmed in the Swedish laboratory in a positive control sample from Denmark.

In conclusion, the $7845+1 \mathrm{G}>\mathrm{A}$ mutation is perceived a deleterious founder mutation located mostly in central Jutland. We have not examined the presence of the mutation in other countries than Denmark and Sweden and draw the attention of other laboratories to the incorrect annotation in the X95165 sequence to avoid clinically important errors.

Acknowledgements

Susan N Rasmussen, Dorte F Jensen, Jette Thinggaard and Flemming H Bergholdt are thanked for excellent technical assistance. This study was supported by the Neye Foundation. 


\section{Figure legends}

Figure 1 Sequence of the exon 15 region

Upper panel: electropherograms for forward sequences of cDNA obtained from a control sample and a patient carrying the $7845+1 \mathrm{G}>\mathrm{A}$ mutation.

Lower panel: Reverse sequences for control and patient sample.

Figure 2 Map of Denmark and South Sweden

The fraction of $7845+1 \mathrm{G}>\mathrm{A}$ mutation compared to the total number of pathogenic BRCA1 and BRCA2 mutations are indicated. The intensity of the gray coloring corresponds to the mutation frequency.

Figure 3 Haplotypes in the BRCA2 region among carriers of the $7845+1 \mathrm{G}>\mathrm{A}$ mutation

The blue regions indicate the longest fragment of the common haplotype in 18 index cases. Red lines indicate SNPs where the genotype breaks the haplotype. The y-axis indicates position on chromosome 13 in base pairs.

\section{Conflicts of interest}

All authors declare no conflicts of interest. 
Table 1 Clinical characteristics of families carrying BRCA2 7845+1G>A

\begin{tabular}{|c|c|c|c|c|}
\hline Family & $\begin{array}{l}\text { Screened } \\
\text { individual (index } \\
\text { person) }\end{array}$ & $\begin{array}{l}\text { Family history of breast and ovarian } \\
\text { cancer }\end{array}$ & Other cancers & LR \\
\hline 1 & $\mathrm{BC} 61(+)$ & $\begin{array}{l}\text { M BC 51; S BC } 54+60(-) ; \text { MA BC; } \\
\text { MA BC }\end{array}$ & B PC 63 & 0.0095 \\
\hline 2 & BC 54 71(+) & & $\begin{array}{l}\text { F PC+VEN 64; } \\
\text { B PC + BOC } 66\end{array}$ & 1.13 \\
\hline 3 & BC 54(+) & M BC 49; S BC $58(+)$ & & 4.38 \\
\hline 4 & $\mathrm{OC}(+)$ & $\begin{array}{l}\text { MA BC } 41+53(+) ; \text { MA BC } 39(+) \\
\text { MA OC } 64 ; \text { MA BC; FC BC } 39(+) ; \\
\text { FC OC } 51 ; \text { FC BC } 62(+) ; \text { FC BC } 39(-)\end{array}$ & $\begin{array}{l}\text { M AB(+); } \\
\text { MU KI } 78+\text { BL } 81 \\
\text { MU TES } 20\end{array}$ & 57.35 \\
\hline 5 & BC 36(+) & PA BC 45 & $\begin{array}{l}\text { F PC 77; M LU 53; } \\
\text { MGF PC 83; PGM VEN } \\
54\end{array}$ & 1.00 \\
\hline 6 & BC $58+$ OC $58(+)$ & MC MBC 62(+) & F LEU(+); MC CER+VEN & 11.39 \\
\hline 7 & BC 44(+) & M OC 50(+); FC OC $36(+)$ & MU AST + GLI 51 & 11.10 \\
\hline 8 & BC 38(+) & M OC 59; FC BC & $\begin{array}{l}\text { F PC; S LEU 6; } \\
\text { PU LU 48; PU VEN } 84 \\
\end{array}$ & 1.00 \\
\hline 9 & BC 44(+) & $\begin{array}{l}\text { S BC } 49(+) ; \text { PA BC } 45 ; \text { PA BC } 36+37(+) ; \\
\text { PA BC } 38 ; \text { PA BC } 42+50 ; \\
\text { PA BC } 47+\text { OC } 60(+) ; \text { PA BC } 35 \\
\text { FC BC } 49 ; \text { FC BC } 30(+) ;\end{array}$ & & 31.39 \\
\hline 10 & $\mathrm{BC} 46(+)$ & MA OC 64+BC 64 & $\begin{array}{l}\text { M HN 77(+); } \\
\text { MU VEN 53; MU VEN }\end{array}$ & 1.08 \\
\hline 11 & BC 50(+) & M BC 43 & MU PC; MU LU & 0.87 \\
\hline 12 & BC $41+$ OC $59(+)$ & $\begin{array}{l}\text { M OC?; S BC 45(+); S BC 48(+); } \\
\text { N BC } 37(+) ; \text { D BC } 45 ; \text { MGM BC } 40(+)\end{array}$ & B SKIN; + & 12.04 \\
\hline 13 & BC 37(+) & M BC 49; MGM OC 72 & FC HN; MU PAN 54 & 1.00 \\
\hline 14 & $\overbrace{}^{1} \mathrm{HN}(+)$ & M BC 70; S OC $68 ;$ S OC 65 & & 1.97 \\
\hline 15 & BC 56(+) & S BC 51; S BC 29+42(+) & & 1.19 \\
\hline 16 & BC 48+53(+) & D BC 25 & F SKIN 75; S RC & 1.00 \\
\hline 17 & BC 27(+) & $\begin{array}{l}\text { PGM OC 50; PGMS BC 70; FFC BC 50; } \\
\text { FFC BC }\end{array}$ & & 4.82 \\
\hline \multirow[t]{2}{*}{18} & BC $47+$ OC 63 & S BC 56(+) & & 1.21 \\
\hline & & & Over all LR & $1,662,078$ \\
\hline
\end{tabular}

BC: female breast cancer, MBC: male breast cancer, OC: ovarian cancer, PC: prostate cancer, TES: testicular cancer, VEN: gastric cancer; AB: abdominal cancer; LEU: leukemia, CER: cervical cancer; AST: astrocytoma, GLI: glioblastoma; HN: head and neck cancer; KI: kidney cancer; BL: bladder cancer; RC: rectum cancer; BOC: bone cancer.

F: father, M: mother, N: niece, PU: paternal uncle, MU: maternal uncle, PA: paternal aunt, MA: maternal aunt, PGM: paternal grandmother, MGM: maternal grandmother, MGF: maternal grandfather, FFC: Father's female cousin, PGMS: paternal grandmothers sister (+): mutation carriers and obligate carriers, (-): individuals tested negative for the mutation.

Individuals labeled with red are potentially in conflict with $7845+1 \mathrm{G}>\mathrm{A}$ being deleterious. LR: likelihood ratio 
Table 2 Geographical distribution of $B R C A 27845+1 \mathrm{G}>\mathrm{A}$ mutation

\begin{tabular}{|l|l|l|l|l|l|}
\hline & $\begin{array}{l}\text { \# mutation } \\
\text { screenings }\end{array}$ & $\begin{array}{l}\text { \#mutations } \\
\text { BRCA1/2 }\end{array}$ & $\mathbf{7 8 4 5 + 1 G > A}$ & $\begin{array}{l}\text { p-value } \\
\text { (analyses) }\end{array}$ & $\begin{array}{l}\text { p-value } \\
\text { (mutations) }\end{array}$ \\
\hline Aalborg & 259 & $28(10.8 \%)$ & $2(7 \%)$ & 0.07 & 0.049 \\
\hline Aarhus & 806 & $89(11.0 \%)$ & $5(5.6 \%)$ & 0.03 & 0.016 \\
\hline Vejle & 466 & $55(11.8 \%)$ & $10(18 \%)$ & 0.00001 & 0.000005 \\
\hline $\begin{array}{l}\text { South } \\
\text { Jutland/Funen }\end{array}$ & 859 & $85(9.9 \%)$ & $1(1.1 \%)$ & 1 & 0.52 \\
\hline East Denmark & 1300 & $190(14.6 \%)$ & $1(0.005 \%)$ & & \\
\hline Total & 3690 & 447 & 19 & & \\
\hline
\end{tabular}

p-values are calculated by comparing the geographical regions to East Denmark.

\section{Reference List}

1 Collaborativ group (2002) Breast cancer and breastfeeding: collaborative reanalysis of individual data from 47 epidemiological studies in 30 countries, including 50302 women with breast cancer and 96973 women without the disease. Lancet 360: 187-195.

2 Gerdes AM, Cruger DG, Thomassen M, and Kruse TA (2006) Evaluation of two different models to predict BRCA1 and BRCA2 mutations in a cohort of Danish hereditary breast and/or ovarian cancer families. Clin.Genet. 69: 171-178.

3 Thorlacius S, Sigurdsson S, Bjarnadottir H, Olafsdottir G, Jonasson JG, Tryggvadottir L, Tulinius H, and Eyfjord JE (1997) Study of a single BRCA2 mutation with high carrier frequency in a small population. Am.J.Hum.Genet. 60: 1079-1084.

4 Dorum A, Hovig E, Trope C, Inganas M, and Moller P (1999) Three per cent of Norwegian ovarian cancers are caused by BRCA1 1675delA or 1135insA. Eur.J.Cancer 35: 779781.doi:S0959804999000507

5 Hansen TV, Ejlertsen B, Albrechtsen A, Bergsten E, Bjerregaard P, Hansen T, Myrhoj T, Nielsen PB, Timmermans-Wielenga V, Andersen MK, Jonson L, and Nielsen FC (2009) A common Greenlandic Inuit BRCA1 RING domain founder mutation. Breast Cancer Res.Treat. 115: 6976.doi:10.1007/s10549-008-0060-Z

6 Abeliovich D, Kaduri L, Lerer I, Weinberg N, Amir G, Sagi M, Zlotogora J, Heching N, and Peretz T (1997) The founder mutations 185delAG and 5382insC in BRCA1 and 6174delT in 
BRCA2 appear in $60 \%$ of ovarian cancer and $30 \%$ of early-onset breast cancer patients among Ashkenazi women. Am.J.Hum.Genet. 60: 505-514.

7 Thomassen M, Hansen TV, Borg A, Lianee HT, Wikman F, Pedersen IS, Bisgaard ML, Nielsen FC, Kruse TA, and Gerdes AM (2008) BRCA1 and BRCA2 mutations in Danish families with hereditary breast and/or ovarian cancer. Acta Oncol. 47: 772-777.doi:791892967 [pii];10.1080/02841860802004974

8 Cruger DG, Kruse TA, and Gerdes AM (2005) 'Indirect' BRCA1/2 testing: a useful approach in hereditary breast and ovarian cancer families without a living affected relative. Clin.Genet. 68: 228233.doi:CGE484 [pii];10.1111/j.1399-0004.2005.00484.X

9 Li Q, Liu Z, Monroe H, and Culiat CT (2002) Integrated platform for detection of DNA sequence variants using capillary array electrophoresis. Electrophoresis 23: 1499-1511.doi:10.1002/15222683(200205)23:10<1499::AID-ELPS 1499>3.0.CO;2-X

10 Hogervorst FB, Cornelis RS, Bout M, van VM, Oosterwijk JC, Olmer R, Bakker B, Klijn JG, Vasen HF, Meijers-Heijboer H, and . (1995) Rapid detection of BRCA1 mutations by the protein truncation test. Nat.Genet. 10: 208-212.doi:10.1038/ng0695-208

11 Mohammadi L, Vreeswijk MP, Oldenburg R, van den Ouweland A, Oosterwijk JC, van der Hout AH, Hoogerbrugge N, Ligtenberg M, Ausems MG, van der Luijt RB, Dommering CJ, Gille JJ, Verhoef S, Hogervorst FB, van Os TA, Gomez GE, Blok MJ, Wijnen JT, Helmer Q, Devilee P, van Asperen CJ, and van Houwelingen HC (2009) A simple method for co-segregation analysis to evaluate the pathogenicity of unclassified variants; BRCA1 and BRCA2 as an example. BMC.Cancer 9: 211-1471-2407-9-211 [pii];10.1186/1471-2407-9-211

12 Wooster R, Bignell G, Lancaster J, Swift S, Seal S, Mangion J, Collins N, Gregory S, Gumbs C, and Micklem G Identification of the breast cancer susceptibility gene BRCA2. Nature.1995 Dec 21 28; 378: 789-92.

13 Bergthorsson JT, Ejlertsen B, Olsen JH, Borg A, Nielsen KV, Barkardottir RB, Klausen S, Mouridsen HT, Winther K, Fenger K, Niebuhr A, Harboe TL, and Niebuhr E (2001) BRCA1 and BRCA2 mutation status and cancer family history of Danish women affected with multifocal or bilateral breast cancer at a young age. J.Med.Genet. 38: 361-368.

14 Gutierrez-Enriquez S, Coderch V, Masas M, Balmana J, and Diez O (2009) The variants BRCA1 IVS6-1G>A and BRCA2 IVS15+1G>A lead to aberrant splicing of the transcripts. Breast Cancer Res.Treat. 117: 461-465.doi:10.1007/s10549-008-0154-7

15 Borg A, Haile RW, Malone KE, Capanu M, Diep A, Torngren T, Teraoka S, Begg CB, Thomas DC, Concannon P, Mellemkjaer L, Bernstein L, Tellhed L, Xue S, Olson ER, Liang X, Dolle J, Borresen-Dale AL, and Bernstein JL (2010) Characterization of BRCA1 and BRCA2 deleterious mutations and variants of unknown clinical significance in unilateral and bilateral breast cancer: the WECARE study. Hum.Mutat. 31: E1200-E1240.doi:10.1002/humu.21202 
